(c) American Dairy Science Association, 2006.

\title{
Feed Stalls Affect the Social and Feeding Behavior of Lactating Dairy Cows
}

\author{
T. J. DeVries ${ }^{1}$ and M. A. G. von Keyserlingk \\ Animal Welfare Program, Faculty of Land and Food Systems, The University of British Columbia, \\ 2357 Main Mall, Vancouver, BC, V6T 1Z4, Canada
}

\begin{abstract}
The first objective of this study was to study the effects of increased bunk space on the frequency of aggressive behavior at the feed bunk and on feed access. The second objective was to determine whether the addition of partitions (feed stalls) between adjacent cows would provide additional protection while feeding, particularly for subordinate cows. Twenty-four lactating Holstein cows were subjected to each of 3 treatments in 3 successive 10 -d treatment periods using a $3 \times 3$ Latin square design. The treatments tested were: 1) $0.64 \mathrm{~m}$ of feed bunk space/cow, 2) $0.92 \mathrm{~m}$ of feed bunk space/ cow, and 3 ) feed stalls $(0.87 \mathrm{~m}$ of feed bunk space/cow with feed stall partitions separating adjacent cows). Time-lapse video was used to quantify the feeding and standing behavior, as well as the aggressive behavior (displacements) displayed by the cows at the feed bunk. To meet our first and second objectives, we compared data from the $0.64 \mathrm{~m} / \mathrm{cow}$ treatment with that from the $0.92 \mathrm{~m} / \mathrm{cow}$ treatment, and data from the $0.92 \mathrm{~m} / \mathrm{cow}$ treatment with that from the feed-stall treatment, respectively. Total daily feeding time increased when feed bunk space was increased from 0.64 to $0.92 \mathrm{~m} / \mathrm{cow}$. Further, the time spent standing in the feeding area while not feeding and the frequency of aggressive interactions at the feed bunk decreased when more bunk space was provided. The addition of feed stalls resulted in more pronounced effects compared with when cows had $0.92 \mathrm{~m} /$ cow of bunk space. The feed stalls also forced cows to change the strategy by which they displaced others from the feed bunk, forcing them to also initiate contact at the rear of the animal they were displacing rather than only from the front and side, as in the other 2 treatments. Further, when the cows were provided with additional feeding space, particularly when combined with feed stalls, those cows with lower social status at the feed bunk experienced the greatest decreases in the number of times they were displaced per
\end{abstract}

Received November 1, 2005.

Accepted March 28, 2006.

${ }^{1}$ Corresponding author: trevorjd@interchange.ubc.ca day. The results indicated that providing increased feed bunk space, particularly when combined with feed stalls, will improve access to the feed and reduce competition at the feed bunk, particularly for subordinate cows.

Key words: feed stall, feeding behavior, competition, dairy cow

\section{INTRODUCTION}

In the dairy industry $0.61 \mathrm{~m}$ of linear feed bunk space has traditionally been regarded as an adequate amount space per lactating dairy cow (Grant and Albright, 2001). In previous research we examined the effect of feed bunk space on the spacing, competitive, and feeding behavior of dairy cows, and found that increasing the amount of feed bunk space above $0.61 \mathrm{~m}$ led to increased spatial separation between cows and fewer aggressive interactions while feeding (DeVries et al., 2004). These changes in spacing and aggressive behavior allowed cows to increase feeding activity, and this effect was the most dramatic for the subordinate animals. In a follow-up study, we demonstrated that decreased stocking density at the feed bunk reduced competition and increased feeding time, regardless of the type of feed barrier used (Huzzey et al., 2006).

Even though the additional feed bunk space in both of these experiments reduced competition at the feed bunk, it did not eliminate it, suggesting that additional factors are contributing to this competition for food resources. Research undertaken with other domesticated species indicates that the configuration of feeding spaces can have profound effects on feeding competition. Several researchers (e.g., Baxter, 1986; Barnett, 1997; Andersen et al., 1999) have investigated the effects of different feed trough partitions on the aggressive behavior of pigs observed during feeding. Without exception, these researchers found that partitions between adjacent feeding animals reduced aggression and displacements at the feed trough and that longer partitions resulted in greater reductions in aggressive behavior.

In many modern dairy systems, dairy cattle are separated from their feed by a post-and-rail feed barrier, 
which allows the cows to move their head to and from the feed as well as from side to side. For cattle, which often displace one another while feeding by swinging and butting with the head, modifications to the barrier that restricts contact between the head of a cow and the head or body of an adjacent cow may be particularly effective in reducing competition. We recently completed 2 studies (Endres et al., 2005; Huzzey et al., 2006) comparing the post-and-rail barrier to the headlock barrier. The headlock barrier provides a limited division (a vertical bar) between the necks of adjacent cows. In both studies, the use of the headlock barrier significantly reduced the incidence of displacements at the feed bunk. However, the use of the headlock did not completely eliminate aggressive behavior at the feed bunk, indicating that the neck division may not provide full protection.

Konggaard (1983) suggested that cows might feel more protected when a physical separation exists between conspecifics during feeding. To date, limited data are available comparing feed barrier designs in freestall facilities that provide a partition between adjacent animals while feeding at the feed bunk. Bouissou (1970) tested different partitions between dominant and subordinate cows at the feed trough to determine which type of partition allowed the subordinate cow to feed for the longest period of time. Bouissou found that partitions separating the heads and those separating the heads and bodies of the individuals significantly increased the feeding times of the subordinate cows. Unfortunately, this research was conducted using only pairs of animals, which prevents extrapolation of the results to larger and more socially complex groups. Further, the cows used by Bouissou were horned, which may explain why the head separations provided the greatest benefit in terms of increased feeding times.

In summary, there is a growing body of evidence suggesting that decreasing stocking density at the feed bunk will reduce competition and increase feed access. Further, researchers have demonstrated in pigs and cattle that providing partitions that separate the bodies of adjacent animals can have profound effects on reducing competition and allow animals to feed for longer periods of time. Based on this research, our first objective was to study the effects of increased bunk space on the frequency of aggressive behavior at the feed bunk and on feed access. Our second objective was to determine whether the addition of partitions (feed stalls) between adjacent cows would provide additional protection while feeding, particularly for subordinate cows.

\section{MATERIALS AND METHODS}

\section{Animals, Housing, and Diet}

Nine primiparous and 15 multiparous (parity $=3.3$ \pm 1.1 ; mean $\pm \mathrm{SD}$ ) lactating Holstein dairy cows were used in the study. The animals were $141.7 \pm 16.4$ DIM at the beginning of the data collection period. The cows were housed in a free-stall barn located at The University of British Columbia Dairy Education and Research Centre (Agassiz, BC, Canada) and were managed according to the guidelines set by the Canadian Council on Animal Care (1993). The cows were fed ad libitum a TMR consisting of $14.7 \%$ corn silage, $21.3 \%$ grass silage, $12.3 \%$ alfalfa hay, and $51.7 \%$ concentrate mash on a DM basis. The composition of the TMR was $47.1 \%$ $\mathrm{DM}$ and contained, on a DM basis, $18.2 \% \mathrm{CP}, 35.2 \%$ $\mathrm{NDF}, 19.0 \% \mathrm{ADF}, 0.88 \% \mathrm{Ca}$, and $0.42 \% \mathrm{P}$. The TMR was formulated according to the NRC (2001) nutrient requirement recommendations for high-producing dairy cows. Cows ate from a feed bunk with access via a post-and-rail feed barrier, which was the same as that described by Huzzey et al. (2006). Animals were delivered feed at approximately 0630 and $1515 \mathrm{~h}$ each day. Feed was pushed up closer to the cows at 1100 , 1830 , and $2230 \mathrm{~h}$ daily. The animals were milked between 0615 and $0645 \mathrm{~h}$ in the a.m. and between 1615 and $1645 \mathrm{~h}$ in the p.m. Milk yields were automatically recorded at each milking.

Representative samples of the TMR were taken for each group at the time of each feed delivery and from the orts on d 5 and 10 of each treatment period. Dry matter content of the samples was determined by ovendrying at $60^{\circ} \mathrm{C}$ for $2 \mathrm{~d}$. Dry matter intake for each group for each day on the treatment was recorded by subtracting the DM weight of the orts from the DM weight of the delivered feed. The daily orts averaged $10.7 \pm$ $4.7 \%$ (mean $\pm \mathrm{SD}$ ) of the delivered feed provided over the course of the experiment. This study was designed to test predictions concerning feeding and competitive behavior and was not designed to test DMI or milk production differences (because of the inability to measure individual DMI and the relatively short treatment periods, respectively); therefore, treatment differences for these later variables were not tested. The cows had an average DMI of $25.0 \pm 1.3 \mathrm{~kg} / \mathrm{d}$ and an average milk yield of $39.9 \pm 7.7 \mathrm{~kg} / \mathrm{d}$ over the course of the experiment.

\section{Experimental Treatments and Design}

The animals were divided into 3 equal groups of 8 cows, which were balanced according to DIM, projected 305 -d milk production $(11,409.4 \pm 1,874.4 \mathrm{~kg})$, and average parity $(2.9 \pm 1.6)$. These groups were created by blocking cows into groups of 3 cows (similar in parity, DIM, and projected 305-d milk production), and then randomly assigning the cows in these blocks to 1 of the 3 experimental groups.

The groups were randomly assigned to 1 of 3 adjacent pens, each having a total of $7.38 \mathrm{~m}$ of accessible feed 
bunk space. Wooden partitions were placed within the feed bunk between the groups to prevent cows from consuming food from adjacent feed bunks. Each experimental pen $($ width $=7.38 \mathrm{~m}$, length $=13.50 \mathrm{~m}$ ) contained 12 free stalls configured in 3 rows. Two rows faced one another, were open at the front ("head-to-head"), and had a bed length of $2.40 \mathrm{~m}$. The third row of free stalls faced a cement wall, and these stalls were $0.30 \mathrm{~m}$ longer to allow more space for getting up and lying down. All free stalls measured $1.20 \mathrm{~m}$ wide center to center, and the neck rail was $1.14 \mathrm{~m}$ above the stall surface. Stalls were deep-bedded with $0.40 \mathrm{~m}$ of sand. The flooring throughout the pens was grooved concrete. The width of the alley between the 4 stalls closest to the feed bunk and the feed bunk was $3.53 \mathrm{~m}$. These 4 stalls closest to the feed bunk were chained off to prevent access by cows such that 8 stalls were available for each group of 8 cows. All groups were housed together for 2 wks to allow for social adaptation prior to the beginning of the experiment.

The treatments tested were: 1 ) $0.64 \mathrm{~m}$ of feed bunk space/cow, 2) $0.92 \mathrm{~m}$ of feed bunk space/cow, and 3) $0.87 \mathrm{~m}$ of feed bunk space/cow with feed-stall partitions (Artex Fabricators Ltd., Langley, BC, Canada) separating adjacent cows (see Figure 1), referred to from here on as "feed stalls." For the $0.64 \mathrm{~m} /$ cow treatment, feed bunk space was adjusted by placing 2 concrete partitions [one measuring $76 \times 76 \times 76 \mathrm{~cm}$ (width $\times$ length $\times$ height $)$ and the other measuring $74 \times 150 \times 79 \mathrm{~cm}]$ in the left side of the feed bunk. For the feed-stall treatment, 7 feed-stall partitions were attached to the postand-rail feed barrier and were spaced such that $0.87 \mathrm{~m}$ of linear bunk space was available for each cow within each stall. Each group was tested within their respective pens with each feed bunk configuration in 3 successive 10-d treatment periods that were assigned to groups using a $3 \times 3$ Latin square design. The treatment periods included $3 \mathrm{~d}$ of treatment adaptation and $7 \mathrm{~d}$ of data collection.

\section{Behavioral Recordings}

All behaviors were monitored using one video camera (Panasonic WV-BP330; Osaka, Japan) located $6 \mathrm{~m}$ above the feed bunk of each pen, a time-lapse videocassette recorder (Panasonic AG-6540), and a video multiplexer (Panasonic WJ-FS 216). Red lights (100 W) were used to facilitate recording at night. Individual cows were identified with unique alphanumeric symbols made with hair dye (Clairol's Nice and Easy \#122, Natural Black, or Clairol's Herbal Essences Bleach Blonde, depending on hair color; Stamford, CT) on the backs of the cows. The aggressive behavior of the cows was measured from continuous recordings of the last $4 \mathrm{~d}$ of each treatment period, whereas the feeding behavior and standing behavior of the cows were recorded continuously for the last $7 \mathrm{~d}$ of each treatment period.

Measuring Aggressive Behavior. Social interactions (displacements from the feed bunk) were noted when an aggressive action (a butt or a push) from one cow (actor) resulted in the complete withdrawal of the head of another cow (reactor) from beneath the feed rail (DeVries et al., 2004). Displacements were differentiated depending on where the actor initiated contact with the reactor's body: the front (head and neck), the side (area between the withers and hips), or the rear (area caudal from the hips).

In addition to using the number of displacements as a dependent variable, these observations were used to calculate an index of success in competitive interactions for each individual cow. For this calculation, the data were combined from all treatments to create one index per cow. The index of success (Mendl et al., 1992; DeVries et al., 2004) was calculated as follows:

[number of cows an individual is able to displace/

(number of cows an individual is able to displace

+ number of cows able to displace the individual)] $\times 100 \%$

Measuring Feeding Behavior and Standing Behavior. The feeding behavior of individual cows, as well as the duration of inactive standing in the feed area, was scored from the video recordings using 10min time sampling. For each scan, an animal was recorded as feeding when its head was completely past the feed rail and over the feed. A cow was recorded as inactively standing if it had all 4 feet within the alley closest to the feed bunk and was not feeding. Total time spent feeding and in inactive standing was calculated by multiplying the number of scans by 10 (Endres et al., 2005; Huzzey et al., 2006). Both time spent feeding and time spent inactively standing were calculated for each cow for each treatment day. Additionally, to detect changes in the daily pattern of feed bunk attendance, these scans were used to calculate the percentage of cows feeding and inactively standing over the course of a 24-h day. We also calculated and averaged the percentage of cows present at the feed bunk and inactively standing during the 90 -min period following the delivery of feed when feeding activity was highest.

\section{Data Analysis}

For the analysis of feeding, standing, and aggressive behavior, the pen was considered the experimental unit, with measures from multiple days and cows averaged to create one observation per pen per treatment. 
A

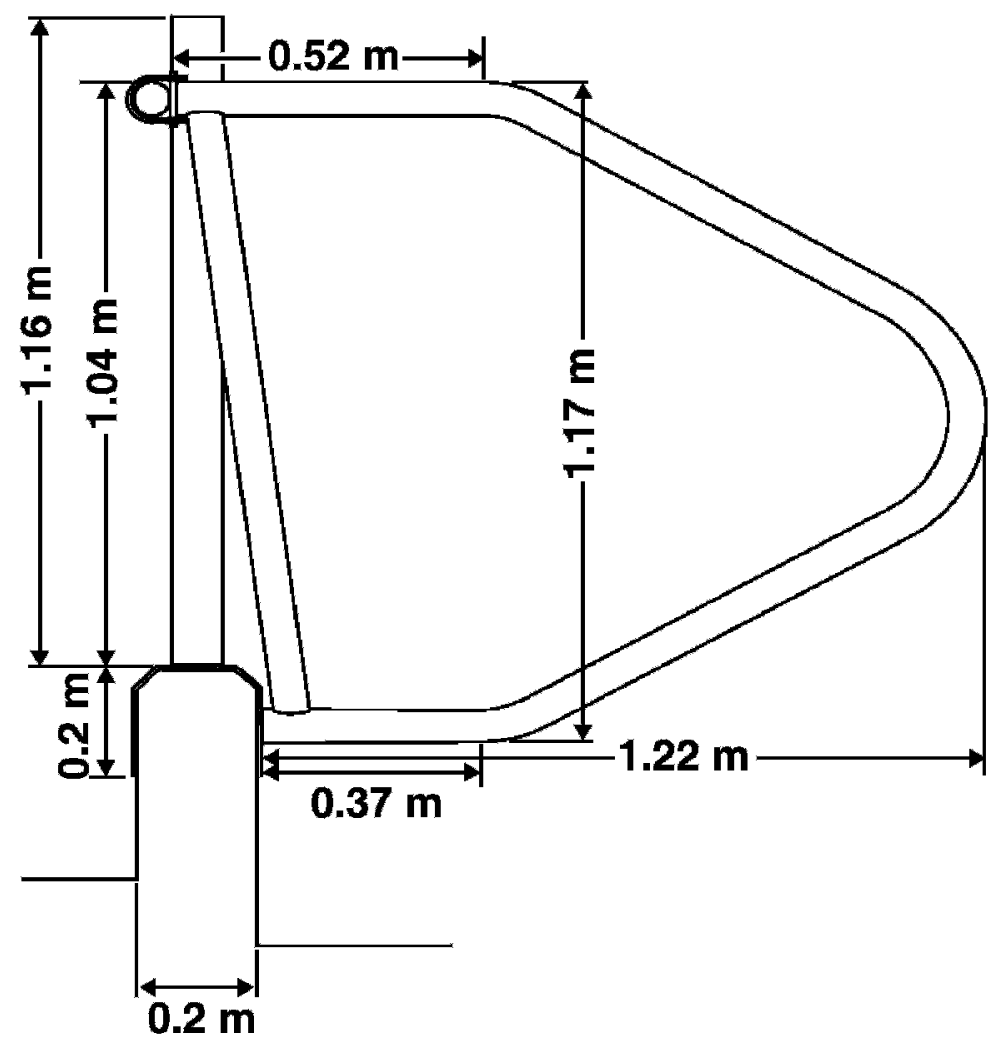

B

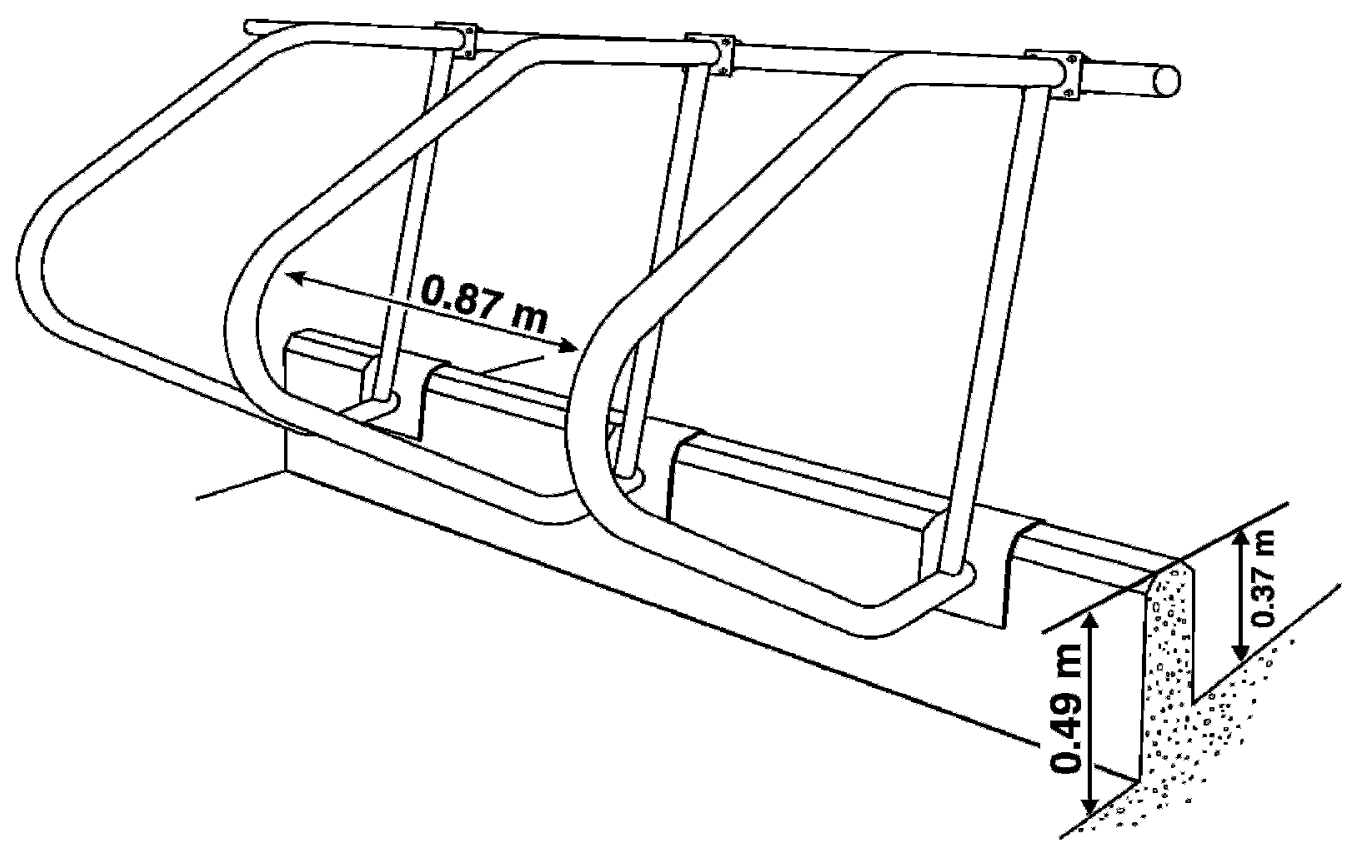

Figure 1. Diagrams of the (A) side and (B) rear-diagonal views of the feed stalls used in this study, showing the dimensions and placement of the feed stalls, respectively. 
There was an interaction between treatment and the time of feeding (i.e., a.m. or p.m.) for the percentage of cows feeding and inactively standing during the 90min period following the delivery of feed; consequently, these data were summarized and analyzed separately for each time of feed delivery. Treatment effects were analyzed as a $3 \times 3$ Latin square with repeated measures using the PROC MIXED procedure of SAS (SAS Institute, 1999). The model included the fixed effect of treatment, the random effects of period and pen, and the residual error. Compound symmetry was selected as the covariance structure on the basis of best fit. To test the effects of increased feed bunk space, and to meet our first objective, we contrasted the means of the $0.64 \mathrm{~m} / \mathrm{cow}$ treatment with those of the $0.92 \mathrm{~m} / \mathrm{cow}$ treatment. To test the effects of the feed stalls, and to meet our second objective, we contrasted the means of the feed-stall treatment with those of the $0.92 \mathrm{~m} / \mathrm{cow}$ treatment, which was the same amount of linear bunk space but in an open feeding design (without feedstall partitions).

To test the hypothesis that socially subordinate cows would be most affected by the treatments, the effects of feed bunk space and feed stalls on the incidence of displacements from the feed bunk were also evaluated, with cow as the observational unit and the cows' index of success as a covariate. These data were again analyzed as a $3 \times 3$ Latin square with repeated measures using the PROC MIXED procedure of SAS (SAS Institute, 1999). The model included the index of success as a covariate, the fixed effect of treatment, the interaction between the index of success and treatment, the random effects of period and cow, and the residual error.

\section{RESULTS}

\section{Aggressive Behavior}

The frequency with which cows were displaced from the feed bunk was significantly reduced when they were given $0.92 \mathrm{~m}$ of feed bunk space/cow compared with when they were given $0.64 \mathrm{~m}$ of feed bunk space/cow (Table 1). This number was further reduced when the cows were provided with feed stalls $(0.87 \mathrm{~m} / \mathrm{cow}$ plus feed stalls). Increased feed bunk space and the addition of feed stalls also changed the method by which cows displaced others from the feed bunk. When cows were provided $0.64 \mathrm{~m}$ of linear bunk space, significantly more displacements were initiated by the actor on the front and side of the reactor compared with when cows were given $0.92 \mathrm{~m}$ of bunk space. There was a further reduction in these types of displacements when the cows were fed using the feed stalls. Although significantly fewer displacements were observed when cows were fed using the feed stalls, a greater proportion of those that did occur were initiated by the actor contacting the rear of the reactor, compared with when the cows were provided with $0.92 \mathrm{~m}$ of bunk space.

The cow-based analysis, considering the cows' index of success, revealed an index of success $\times$ treatment interaction $(P<0.001)$, demonstrating that cows with lower indices of success had the greatest decrease in the number of times they were displaced per day when they were provided with either $0.92 \mathrm{~m} / \mathrm{cow}$ of feed bunk space or with the feed stalls.

\section{Feeding Behavior}

Daily feeding time of the cows was longer when they were provided with $0.92 \mathrm{~m}$ of feed bunk space/cow than when they were given $0.64 \mathrm{~m}$ of bunk space/cow (Table 2). Further, there was a tendency for daily feeding time to be longer when the cows had feed stalls than when they had $0.92 \mathrm{~m}$ of open bunk space. The attendance patterns of cows at the feed bunk (Figure 2) were influenced when more bunk space was provided and with the addition of feed stalls. During the a.m. peak feeding period, there was no difference among treatments in the percentage of cows present at the feed bunk (Table 3). However, during the p.m. peak feeding period, a higher percentage of cows fed at the feed bunk when $0.92 \mathrm{~m}$ of bunk space was provided than when $0.64 \mathrm{~m}$ of bunk space was provided. Further, more cows were present at the feed bunk in the feed stalls during this period than during the treatment when cows were given $0.92 \mathrm{~m} /$ cow.

\section{Standing Behavior}

The daily time spent by the cows in inactive standing was higher when $0.64 \mathrm{~m}$ of feed bunk space was provided than when they had $0.92 \mathrm{~m}$ of bunk space (Table 2). There was also a tendency for the inactive standing time to be lower when cows were fed using the feed stalls compared with when they had $0.92 \mathrm{~m}$ of bunk space. Similar to the treatment effect of increased bunk space on feeding behavior, the effect of increased space on inactive standing times of cows was most pronounced during the times of peak feeding activity. During the a.m. peak feeding period, there was a tendency for more cows to stand inactively when they had $0.64 \mathrm{~m}$ of feed bunk space than when they had $0.92 \mathrm{~m}$ of space (Table 3). Similarly, in the p.m. peak feeding period, a significantly higher percentage of cows stood inactively when they had $0.64 \mathrm{~m}$ of feed bunk space compared with when they had $0.92 \mathrm{~m}$ of bunk space. During this p.m. period, there was also a tendency for a lower percentage of cows to stand inactively when they had feed stalls than when they had $0.92 \mathrm{~m}$ of bunk space. 
Table 1. Incidence of displacements from the feed bunk and the point of initial contact that resulted in a displacement at the feed bunk with $0.64 \mathrm{~m}$ of feed bunk space/cow, $0.92 \mathrm{~m}$ of feed bunk space/cow, and feed stalls $(0.87 \mathrm{~m} \text { of bunk space/cow with feed-stall partitions })^{1}$

\begin{tabular}{lllllll}
\hline & \multicolumn{3}{c}{ Treatment } & & & $P$ \\
\cline { 2 - 7 } $\begin{array}{l}\text { Displacements, } \\
\text { no./cow per d }\end{array}$ & $0.64 \mathrm{~m}$ & $0.92 \mathrm{~m}$ & $\begin{array}{l}\text { Feed } \\
\text { stall }\end{array}$ & SE & Space & $\begin{array}{l}\text { Feed } \\
\text { stall }\end{array}$ \\
\hline Total & 9.74 & 5.59 & 2.54 & 0.26 & 0.003 & 0.006 \\
Front & 6.47 & 4.08 & 1.26 & 0.21 & 0.009 & 0.006 \\
Side & 3.08 & 1.46 & 0.73 & 0.11 & 0.007 & 0.03 \\
Rear & 0.19 & 0.05 & 0.55 & 0.07 & 0.18 & 0.02 \\
\hline
\end{tabular}

${ }^{1}$ Data were averaged for $4 \mathrm{~d}$ per treatment of 3 groups of cows ( 8 cows per group). The least squares $\mathrm{SE}$ and $P$ values for the test of treatment are provided. $P=$ the probability for contrasts: space $=0.64 \mathrm{~m}$ vs. $0.92 \mathrm{~m}$; feed stall $=0.92 \mathrm{~m}$ vs. feed stalls.

${ }^{2}$ Total $=$ number of displacements from the feed bunk per cow per day. Front $=$ number of displacements per cow per day in which the actor made contact with the front (head and neck) of the reactor's body. Side = number of displacements per cow per day in which the actor made contact with the side (area between the withers and hips) of the reactor's body. Rear = number of displacements per cow per day in which the actor made contact with the rear (area caudal from the hips) of the reactor's body.

\section{DISCUSSION}

The results of the present study provide additional support for our previous conclusions that lactating dairy cows experience less competition and improved access to feed when they are provided with more than the industry standard of $0.61 \mathrm{~m}$ of feed bunk space per animal (DeVries et al., 2004; Huzzey et al., 2006). In this study, increasing the availability of space at the feed bunk decreased the number of aggressive interactions at the bunk. When cows were provided with 0.92 $\mathrm{m}$ of bunk space/cow, the average number of times a cow was displaced from the feed bunk was only $57 \%$ of the level seen for the treatment at $0.64 \mathrm{~m}$ of space. This result agrees with previous findings of our research group. DeVries et al. (2004) reported that when cows were provided with $1.0 \mathrm{~m}$ of space/cow, the average number of times a cow displaced another from the feed bunk during peak feeding periods was only $43 \%$ of the level seen during that same time period for the treatment with $0.5 \mathrm{~m}$ of space/cow. Similarly, in the doseresponse study by Huzzey et al. (2006), the average number of times a cow was displaced from the feed bunk when provided with $0.81 \mathrm{~m}$ of feed bunk space/ cow was lower than the level seen for the treatment with $0.61 \mathrm{~m}$ of space. A similar effect of feeding space has also been noted in pigs: Baxter (1986) demonstrated that when pigs were provided with more feeding space, they tended to be less aggressive while feeding.

The results indicated that the displacements that occurred during the 0.64 and $0.92 \mathrm{~m} / \mathrm{cow}$ treatments were similar in type. When cows were provided with either 0.64 or $0.92 \mathrm{~m}$ of bunk space/cow, the majority of the displacements were initiated by physical contact occurring at either the front or side of the reactor. This observation indicates that cows were using the same strategy when displacing other cows from the feed bunk, but that they decreased the frequency of this behavior when provided with more space.

In the present study we also observed that when feed bunk space was increased from 0.64 to $0.92 \mathrm{~m} / \mathrm{cow}$, the daily feeding time increased by $4.6 \%$. This result is in agreement with our previous findings. In the study by Huzzey et al. (2006), we noted that a moderate increase in feed bunk space (from 0.61 to $0.81 \mathrm{~m} / \mathrm{cow}$ ) resulted

Table 2. Measures of feeding time and inactive standing behavior with $0.64 \mathrm{~m}$ of feed bunk space/cow, 0.92 $\mathrm{m}$ of feed bunk space/cow, and feed stalls $(0.87 \mathrm{~m} \text { of bunk space/cow with feed-stall partitions })^{1}$

\begin{tabular}{lcccccc}
\hline & \multicolumn{3}{c}{ Treatment } & & \multicolumn{2}{c}{$P$} \\
\cline { 2 - 5 } & $0.64 \mathrm{~m}$ & $0.92 \mathrm{~m}$ & $\begin{array}{l}\text { Feed } \\
\text { stall }\end{array}$ & SE & Space & $\begin{array}{l}\text { Feed } \\
\text { stall }\end{array}$ \\
\hline Feeding time $^{2}$ & 314.3 & 328.9 & 339.5 & 9.1 & 0.02 & 0.06 \\
Inactive standing $^{3}$ & 93.5 & 70.5 & 63.9 & 6.5 & 0.01 & 0.1 \\
\hline
\end{tabular}

${ }^{1}$ Data were averaged for $7 \mathrm{~d}$ per treatment of 3 groups of cows ( 8 cows per group). The least squares SE and $P$ values for the test of treatment are provided. $P=$ probability for contrasts: space $=0.64 \mathrm{~m}$ vs. 0.92 $\mathrm{m}$; feed stall $=0.92 \mathrm{~m}$ vs. feed stalls.

${ }^{2}$ Average feeding time/d per cow.

${ }^{3}$ Average time spent standing inactively/d per cow. 


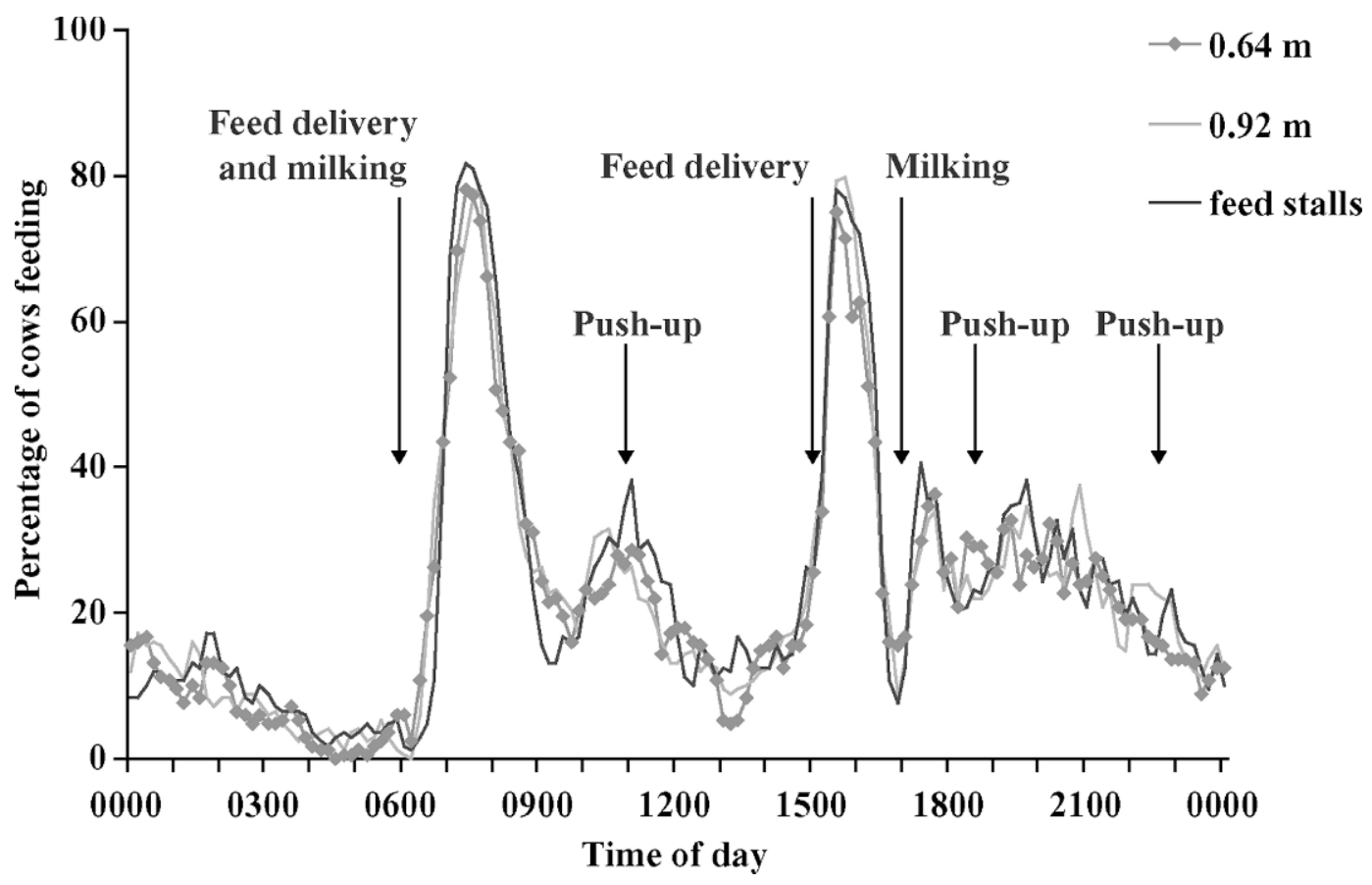

Figure 2. Percentage of cows per group present at the feed bunk over a 24-h period (percentage for each 60 -s interval during the day) for 3 treatments: 1) $0.64 \mathrm{~m}$ of feed bunk space/cow, 2) $0.92 \mathrm{~m}$ of feed bunk space/cow, and 3) feed stalls $(0.87 \mathrm{~m}$ of bunk space/cow with feed-stall partitions). Data were averaged for $7 \mathrm{~d}$ per treatment of 3 groups, each containing 8 cows.

in a $1.2 \%$ increase in daily feeding time. Similarly, when we doubled the amount of feed bunk space from 0.5 to $1.0 \mathrm{~m} / \mathrm{cow}$ (DeVries et al., 2004), the daily feeding time of the cows increased by $14 \%$. The results of the present study, combined with those from our previous studies, indicate that lactating dairy cattle appear to realize greater benefits in terms of increased time spent feeding when provided with increased amounts of available feeding space.
In the current study, cows spent 23 min longer per day standing in the feeding area while not feeding (inactive standing) when they had $0.64 \mathrm{~m}$ of feed bunk space compared with when they had $0.92 \mathrm{~m}$ of bunk space. Increased inactive standing time in response to increased stocking density at the feeding area has previously been reported (Olofsson, 1999; Huzzey et al., 2006). As we suggested in Huzzey et al. (2006), this behavior may have long-term negative hoof health ef-

Table 3. Percentage of cows per group at the feed bunk and standing inactively averaged over the period of peak feeding activity (90 min following the delivery of fresh feed) with $0.64 \mathrm{~m}$ of feed bunk space/cow, $0.92 \mathrm{~m}$ of feed bunk space/cow, and feed stalls $(0.87 \mathrm{~m} \text { of bunk space/cow with feed-stall partitions })^{1}$

\begin{tabular}{llcccccc}
\hline & \multicolumn{3}{c}{ Treatment } & & \multicolumn{2}{c}{$P$} \\
\cline { 2 - 4 } & & & & Feed & & Feed \\
Variable, \% & $0.64 \mathrm{~m}$ & $0.92 \mathrm{~m}$ & stall & & SE & Space & stall \\
\hline Cows at the feed bunk $^{2}$ in a.m. & 70.1 & 70.8 & 73.5 & 4.7 & 0.8 & 0.35 \\
Cows at the feed bunk in p.m. & 62.3 & 64.4 & 67.1 & 2.7 & 0.05 & 0.03 \\
Cows standing inactively $^{3}$ in a.m. & 7.2 & 3.8 & 3.8 & 0.9 & 0.08 & 0.95 \\
Cows standing inactively in p.m. & 8.4 & 5.9 & 4.2 & 1.0 & 0.03 & 0.07 \\
\hline
\end{tabular}

${ }^{1}$ Data were averaged for $7 \mathrm{~d}$ per treatment of 3 groups of cows ( 8 cows per group). The least squares SE and $P$ values for the test of treatment are provided. $P=$ probability for contrasts: space $=0.64 \mathrm{~m}$ vs. 0.92 $\mathrm{m}$; feed stall $=0.92 \mathrm{~m}$ vs. feed stalls.

${ }^{2}$ Percentage of cows per group at the feed bunk averaged over the period of peak feeding activity (90 min following the delivery of fresh feed).

${ }^{3}$ Percentage of cows per group standing inactively averaged over the period of peak feeding activity (90 min following the delivery of fresh feed). 
fects; however, more research is needed to establish the relationship between stocking density, standing behavior, and hoof health. Similar to the findings reported in Huzzey et al. (2006), we found that the greatest differences in inactive standing occurred during the periods of peak feeding activity. This was likely because cows were highly motivated to access freshly delivered feed (DeVries and von Keyserlingk, 2005), and in situations in which feed space was limited because of high occupancy, some cows were forced to stand and wait for an available feeding spot. This may have unintended nutritional consequences for those cows that do not have access to feed at the time of delivery. Sorting of the TMR can reduce the quality of the feed, particularly in the later hours past the time of feed delivery (DeVries et al., 2005). Therefore, in situations in which high stocking densities at the feed bunk force some cows to wait for access while others occupy the feed bunk, those waiting may end up consuming a ration that is not balanced to meet their nutritional requirements.

The second objective of this study was to determine whether the addition of feed stalls would provide additional protection to the cows while feeding, particularly for subordinate cows. To our knowledge, this is the first study to determine the effects of feed stalls on the aggressive behavior of group-housed lactating dairy cows. The addition of the feed stalls greatly decreased the number of aggressive interactions at the feed bunk. The average number of times a cow was displaced from the feed bunk that had feed stalls was only $45.5 \%$ of the level seen for the $0.92-\mathrm{m}$ treatment. Several researchers have investigated the effects of different feed trough partitions on the level of aggressive behavior pigs exhibit during feeding (Baxter, 1986; Barnett, 1997; Andersen et al., 1999). Similar to our findings, all these researchers found that partitions reduced the level of aggressive behavior at the feed trough. Interestingly, these researchers all noted that the longer the partitions were, the greater was the decrease in aggressive behavior.

In some of our previous work (Endres et al., 2005; Huzzey et al., 2006), we compared the post-and-rail feed barrier with the headlock feed barrier. In these studies, the use of the headlock barrier significantly reduced the incidence of aggressive displacements at the feed bunk, regardless of stocking density at the feed bunk. In Huzzey et al. (2006), we hypothesized that this reduction in aggressive behavior could be attributed to cattle having more difficulty swinging their head from side to side while competing for the food resource when fed using the headlock barrier, which provides a physical barrier (a vertical bar) between the necks of the cows.
In the present study the dramatic decline in the number of displacements when cows were fed using the feed stalls can be explained by the design of the feed stall. The presence of the vertical bar at the front of the partition likely contributed to the $69 \%$ decrease in the number of displacements that stemmed from contact initiated at the front of the reactor. The vertical bar likely minimized any attempts by a cow to swing her head from side to side in an attempt to displace another cow. The presence of the body partitions located between adjacent cows may have contributed further to the reduction in aggressive behavior. These partitions likely contributed to the $50 \%$ reduction in the number of displacements instigated at the side of the reactor that occurred when cows had feed stalls, compared with the $0.92 \mathrm{~m}$ of open bunk space.

Interestingly, when cows were allowed access to the TMR using the feed stalls, the strategy used by the actor to displace another cow changed dramatically, even though the amount of linear bunk space was similar between the $0.92 \mathrm{~m} / \mathrm{cow}$ of open bunk space and the feed-stall $(0.87 \mathrm{~m} / \mathrm{cow})$ treatments. In contrast to the 0.92 treatment, the presence of the feed stalls resulted in more displacements being instigated by the actor making contact on the rear of the reactor. In fact, $21.7 \%$ of the total daily displacements were instigated from the rear when the cows were provided with the feed stalls, compared with only $0.9 \%$ of the total daily displacements instigated from the rear when cows were provided with $0.92 \mathrm{~m} / \mathrm{cow}$. It is interesting to note that despite the change in strategy used to displace others when the feed stalls were present, cows were not as effective in doing so, resulting in a decrease in the total daily number of displacements.

The overall reduction in aggressive interactions at the feed bunk most likely contributed to the trend by cows to spend increased daily time feeding when provided with feed stalls, compared with simply providing more space. This result also agrees with the findings of Bouissou (1970), who found that partitions at the feeding area that separated the heads of adjacent animals and those that separated both the heads and bodies of side-by-side individuals allowed subordinate cows to feed for longer periods of time than when no division was used. A similar effect has also been shown in grouphoused pregnant sows: Time at the feed trough was found to increase as the length of partitions between the feeding sows was increased (Andersen et al., 1999). It is interesting to note that in Huzzey et al. (2006), we found that at a decreased stocking density $(0.81 \mathrm{~m}$ per cow), cows spent more time feeding when using a postand-rail vs. a headlock feed barrier. In that study, we suggested that the post-and-rail provided less of a physical barrier between the cows and the feed, which may 
have made feeding more comfortable for the cows. We also suggested that cows may have developed a learned aversion to the headlocks because of their use in management practices that require cows to be restrained, possibly making cows reluctant to cross the barrier. The difference between our present findings and those in Huzzey et al. (2006) may be attributed to the design of the feed stalls. Even though the feed stalls contained a vertical bar between the necks of adjacent cows, similar to the headlock, the spatial separation between the vertical bars was much greater for the feed stalls used in our study. Unlike the headlock, which is restrictive, the feed stall allows the cow to move her head freely while feeding. Additionally, the design of the feed stalls creates a defined feeding position for each cow and, as previously mentioned, dramatically reduces displacements from the feed bunk. Therefore, it seems likely that these factors make feeding more comfortable for the cows, allowing them to feed for longer periods of time.

These potential benefits in comfort while feeding may have contributed to the finding that the cows spent less time standing inactively in the feeding area when the feed stalls were present. This decrease in inactive standing was particularly noticeable during the peak feeding period following the afternoon delivery of feed. During that time period, there was a tendency for a lower percentage of cows to stand inactively and an increase in the percentage of cows present at the feed bunk. No differences were noted for the a.m. period; however, this may be explained by the suggestion that lactating dairy cows do not show the same intensity in feeding activity in the a.m. as in the p.m. (DeVries et al., 2003).

The cow-based analysis indicated that the subordinate cows received the most benefit from the increased feed bunk space and the addition of feed stalls. In both comparisons, we noted that the subordinate cows experienced the greatest decrease in the number of times they were displaced per day. These results are similar to the findings in Huzzey et al. (2006), in which we reported that subordinate cows were displaced more often with the post-and-rail barrier design, particularly at high stocking densities. In the study by Andersen et al. (1999), lower-ranked sows were subjected to less aggression and fewer displacements as the length of the partitions was increased. Thus, it appears that the additional feeding space, particularly when combined with feed stalls, improves the feeding conditions for those subordinate animals that may, under typical housing situations, have difficulty accessing feed at times when they have the greatest desire to feed. Therefore, decreasing stocking density at the feed bunk and the addition of feed stalls makes it easier for all cows to access fresh feed, which, as previously mentioned, will act to reduce the between-cow variation in TMR consumed. This may be particularly important for early-lactation cows, which often experience difficulty in meeting their nutritional requirements and succumb to disease (Drackley, 1999).

Because this study was designed to test the effects of feed bunk space and the use of feed stalls on the feeding and competitive behavior of lactating dairy cows, we were unable to test the long-term effects on DMI, milk production, and health or the economic feasibility of these treatments. Therefore, we recommend that future studies concerning feed bunk design and stocking density be designed to examine these effects.

\section{CONCLUSIONS}

Increasing the feed bunk space from 0.64 to $0.92 \mathrm{~m} /$ cow resulted in a reduction in time spent standing in the feeding area while not feeding, a decrease in the frequency of aggressive interactions at the feed bunk and an increase in daily feeding time. Time spent standing in the feeding area while not feeding and aggressive interactions at the feed bunk were further reduced and feeding time was further increased by the addition of feed stalls. The feed stalls also forced cows to change the strategy by which they displaced others from the feed bunk, forcing them to also initiate contact at the rear of the animal they were displacing rather than only from the front and side as in the other 2 treatments. We also found that with the additional feeding space, particularly when combined with feed stalls, those cows ranked lower in the social hierarchy at the feed bunk had the greatest decreases in the number of times they were displaced per day. Based on these results, we recommend decreasing the stocking density at the feed bunk and using feed stalls to improve feed access and reduce competition at the feed bunk, particularly for subordinate animals. Future work is now required to fully understand the long-term implications of increased feed access and reduced competition at the feed bunk on the DMI, milk production, and health of lactating dairy cows, particularly those in early lactation.

\section{ACKNOWLEDGMENTS}

We thank the staff and students at The University of British Columbia's Dairy Education and Research Centre and the University's Animal Welfare Program. In particular we thank Kiyomi Ito for her help with the video analysis, Audrey Nadalin for her help with the feed sample drying, Dan Weary for his comments on the statistical design and analyses, and Julie Huzzey 
for her comments on the manuscript. Trevor DeVries was supported by a Natural Sciences and Engineering Research Council of Canada (NSERC) Canada Graduate Scholarship. This project was funded by NSERC, through the Industrial Research Chair in Animal Welfare, and by contributions from the Dairy Farmers of Canada, the British Columbia Dairy Foundation, the British Columbia Society for the Prevention of Cruelty to Animals, members of the British Columbia Veterinary Medical Association, and many other donors listed on the Animal Welfare Web site at http://www.landfood. ubc.ca/animalwelfare.

\section{REFERENCES}

Andersen, I. L., K. E. Bøe, and A. L. Kristiansen. 1999. The influence of different feeding arrangements and food type on competition at feeding in pregnant sows. Appl. Anim. Behav. Sci. 65:91-104.

Barnett, J. L. 1997. Modifying the design of group pens with individual feeding places affects the welfare of pigs. Pages 613-618 in Proc. 5th Int. Livest. Environ. Symp. R. W. Bottcher and S. J. Hoff, ed. American Society of Agricultural Engineers, St. Joseph, MI.

Baxter, M. R. 1986. The design of the feeding environment for the pig. Ph.D. Dissertation, University of Aberdeen, Aberdeen, UK.

Bouissou, M.-F. 1970. Role du contact physique dans la manifestation des relations hierarchiques chez les bovines. Consequences pratiques. Ann. Zootech. 19:279-285.

Canadian Council on Animal Care. 1993. Guide to the Care and Use of Experimental Animals. Vol. 1. E. D. Olfert, B. M. Cross, and A. A. McWilliam, ed. Canadian Council on Animal Care, Ottawa, Canada.
DeVries, T. J., and M. A. G. von Keyserlingk. 2005. Time of fresh feed delivery affects the feeding and lying patterns of dairy cows. J. Dairy Sci. 88:625-631.

DeVries, T. J., M. A. G. von Keyserlingk, and K. A. Beauchemin. 2003. Diurnal feeding pattern of lactating dairy cows. J. Dairy Sci. 86:4079-4082.

DeVries, T. J., M. A. G. von Keyserlingk, and K. A. Beauchemin. 2005. Frequency of feed delivery affects the behavior of lactating dairy cows. J. Dairy Sci. 88:3553-3562.

DeVries, T. J., M. A. G. von Keyserlingk, and D. M. Weary. 2004. Effect of feeding space on the inter-cow distance, aggression, and feeding behavior of free-stall housed lactating dairy cows. J. Dairy Sci. 87:1432-1438.

Drackley, J. K. 1999. Biology of dairy cows during the transition period: The final frontier? J. Dairy Sci. 82:2259-2273.

Endres, M. I., T. J. DeVries, M. A. G. von Keyserlingk, and D. M. Weary. 2005. Effect of feed barrier design on the behavior of loosehoused lactating dairy cows. J. Dairy Sci. 88:2377-2380.

Grant, R. J., and J. L. Albright. 2001. Effect of animal grouping on feeding behavior and intake of dairy cattle. J. Dairy Sci. 84(Suppl. E):E156-E163.

Huzzey, J. M., T. J. DeVries, P. Valois, and M. A. G. von Keyserlingk. 2006. Stocking density and feed barrier design affect the feeding and social behavior of dairy cattle. J. Dairy Sci. 89:126-133.

Konggaard, S. P. 1983. Feeding conditions in relation to welfare for dairy cows in loose-housing systems. Pages 272-280 in Farm Animal Housing and Welfare. S. H. Baxter, M. R. Baxter, and J. A. D. MacCormack, ed. Martinus Nijhoff, Dordrecht, The Netherlands.

Mendl, M., A. J. Zanella, and D. M. Broom. 1992. Physiological and reproductive correlates of behavioural strategies in female domestic pigs. Anim. Behav. 44:1107-1121.

NRC (National Research Council). 2001. Nutrient Requirements for Dairy Cattle. National Academy of Sciences, Washington, DC.

Olofsson, J. 1999. Competition for total mixed diets fed for ad libitum intake using one or four cows per feeding station. J. Dairy Sci. 82:69-79.

SAS Institute. 1999. SAS Users Guide. SAS Institute Inc., Cary, NC. 